\title{
Investigating the impact of track gradients on traction energy efficiency in freight transportation by railway
}

\author{
G. Bureika \& G. Vaičiūnas \\ Department of Railway Transport, \\ Vilnius Gediminas Technical University, Lithuania
}

\begin{abstract}
Energy recovery is an effective method of energy saving which can be used for traction in freight transportation by railway. In this area, energy recovery is a process of converting the kinetic energy of a moving train in electricity, which is transferred to another energy consumer (another train using the traction energy) through a catenary. Energy recovery can be effectively used for carrying various raw materials (e.g. timber, oil, etc.) to seaports by railway. The loaded wagons which are much heavier than unloaded wagons carry goods "down" to the seaports, while empty trains return (i.e. go 'upward') to the continent. The seaports are only several meters above the sea level, while the places of freight dispatching can be hundreds of meters, or even kilometres, above the sea level. The asymmetry of freight flows (when the freight flow directed "downwards" is several times heavier than 'upward' freight flow) may be effectively used for energy recovery. The research performed shows that, given an appropriate combination of the asymmetry of the freight flows in opposite directions and particular track gradient, the potential energy of freight trains may be used for freight transportation by applying energy recovery techniques. This allows the authors to make an assumption that this could serve a theoretical basis for making feasible one-way freight transportation by using only the recovered energy of the train. On the other hand, taking into account the rolling resistance of the train, there should be some limiting values of the ratio of the freight flows in the opposite directions, and the track gradient should not have small values (e.g. track gradient or the ratio of freight flows should not be too low). If that is the case, the inertial freight transportation is not possible, and an external energy source sufficient to overcome the rolling resistance of the train is required.
\end{abstract}


Finally, the paper presents the ideas how to effectively use the potentialities of energy recovery technique in freight transportation by railway.

Keywords: locomotive traction, freight transportation, track gradient, track curve, freight flow asymmetry coefficient, energy recovery ratio.

\section{Introduction}

Since railway lines are neither straight nor horizontal, the moving trains should overcome track gradients and curves using additional energy [1]. On the other hand, these gradients could be used for energy recovery, which is an effective process of saving energy in the area of railway transportation. Energy recovery is the conversion of the kinetic energy of a train into electric energy by braking or inertial moving of the train down the steep hill and energy transmission to other consumers (usually, to another train via the contact power network or catenary) $[4,5]$. This method of energy saving has advantages and disadvantages. First, there should be a consumer of the recovered energy (or means of energy storage) on the same route. Usually, this recovered energy is consumed by another electric (or hybrid) locomotive, which is moving in traction mode [3]. This means that to ensure energy consumption, railway traffic should be sufficiently intense. Another limitation is the requirement that a braking train should generate the amount of energy which should be sufficient to make energy recovery system (network) effective. This implies that the speed and weight of the train should be considerable; therefore, there should be a considerable track gradient on the route. Energy recovery technology is particularly effective, when the train is running downhill at high speed (e.g. when speed of the train is up to $80 \mathrm{~km} / \mathrm{h}$, while the gradient is about $10 \%$ ). Braking is not necessarily aimed at bringing the train to a stop. It may aim at maintaining the uniform speed of the train running downhill. In this case, the potential energy of the train is converted to electricity rather than to the kinetic energy, because the train does not accelerate. The conversion of potential energy to electric energy in the process of energy recovery has various technical applications. For example, the potential energy of the ascending funicular car is used for pulling another car, with a certain amount of the energy, also used to overcome friction). The principle of energy recovery may be used to lift a residential building. If the total mass of people ascending and taking a lift to the top floors is assumed to be equal to the mass of people descending by the lift and leaving the building, the total potential energy will be a nearly constant value for a long period of time. It follows that when the potential energy of the descending people is stored and used for lifting other people, the total energy consumption will consist only of losses caused by friction of the lift mechanism and energy conversion (transformation) losses. This principle can be also used in freight transportation by railway. If a train is moving uphill, the recovered energy of the train moving downhill (with a certain amount of power from the mains) may be used to pull it. Energy recovery may be particularly useful for freight transportation by railways, used for carrying various materials (e.g. oil products, timber, etc.) to the seaports. The loaded trains, which are up to four times as heavy as the empty ones, are moving 
"down" to the seaports, while empty, light trains, are running from the seaports "up" to the continent [6]. This asymmetry of the freight flows (when the flow of goods carried "downwards" is several times larger than the flow of goods carried "upwards" may be effectively used for energy recovery. If people were only descending (but not ascending) in funiculars or lifts, these mechanisms could operate without any external source of energy, however, an effective energy recovery system should be provided. It is hardly possible to have freight trains that would be using only the potential energy of freight, i.e. operating without using any external energy source. However, the recovered potential freight energy makes a considerable part of the energy consumed by trains for traction. A mathematical model (equation) given below describes the dependence of this amount of energy for the trains with respect to the operating conditions, e.g. their running resistance, road profile, etc.

\section{A theoretical study of energy recovery of moving trains}

The movement of the train is always associated with primary running resistance $W_{0}$, defined as an empirical function of the train speed $\mathrm{v}$ and train squared speed $v^{2}$. The train speed determines the frictional forces of rolling wheels and energy dissipation, while aerodynamic resistance of the running train depends on the squared speed. In the theoretical study of energy recovery described below, relative resistance $w_{0}$ of the running train, determining the value of primary resistance per ton of the train mass, is considered. Thus, primary relative resistance $w_{0}$ depends on the axle load $q_{a}$, i.e. determines the loading of the wagons (ranging from empty to fully loaded wagons).

In a general case, the amount of energy required for performing the work of pulling the wagons of the train is calculated by the equation:

$$
e_{0}=S \cdot\left(Q \cdot w^{\prime \prime}+P \cdot w^{\prime}\right)
$$

where $S$ is the length of the track, km; $Q$ is the mass of wagons, $\mathrm{t} ; P$ is the locomotive mass, $\mathrm{t} ; w^{\prime \prime}$ is a relative running resistance of wagons, taking into account wheel rolling resistance, aerodynamic resistance and track gradient resistance, $\mathrm{kgf} / \mathrm{t} ; w^{\prime}$ is a relative locomotive running resistance, taking into account wheel rolling resistance, aerodynamic resistance and track gradient resistance, $\mathrm{kgf} / \mathrm{t}$.

Let us assume that 'a common statistical train' with the locomotive mass $P$ and the mass of wagons $Q_{\text {down }}$ is running 'downwards' at speed v, while another train with locomotive mass $P$ and the mass of wagons $Q_{u p}$ is moving 'upwards'. In this case, when the train is moving downhill, track gradient resistance $W_{i}$ is developed. In the calculation of the relative track gradient resistance $w_{i}[\mathrm{kgf} / \mathrm{t}]$, its numerical value is equal to track gradient $i$ value [\%o]. Taking this into account, the amount of the recovered energy (the potential) will be as follows:

$$
e_{\text {down }}=S \cdot\left(Q_{\text {down }} \cdot\left|-i+w_{\text {down }}^{\prime \prime}\right|+P \cdot\left|-i+w_{0}^{\prime}\right|\right),
$$


where $S$ is the path covered by the train, $\mathrm{km} ; i$ is track gradient, \%o; $w_{\text {down }}^{\prime \prime}$ is the main relative running resistance of the wagons, $\mathrm{kgf} / \mathrm{t} ; w_{0}^{\prime}$ is the main relative running resistance of the locomotive, $\mathrm{kgf} / \mathrm{t}$.

The expected amount of the recovered energy may be expressed by the equation:

$$
e_{\text {down }}=S \cdot\left(Q_{\text {down }} \cdot\left|-i+w_{\text {down }}^{\prime \prime}\right|+P \cdot\left|-i+w_{0}^{\prime}\right|\right) \cdot k_{\text {rec }},
$$

where $k_{\text {rec }}$ is energy recovery ratio (usually ranging from 0 to 1 ).

Energy consumption on the 'upwards' moving train will be as follows:

$$
e_{u p}=S \cdot\left(Q_{u p} \cdot\left(i+w_{u p}^{\prime \prime}\right)+P \cdot\left(i+w_{0}^{\prime}\right)\right) .
$$

The mass of the 'upwards' moving train will be expressed by the equation:

$$
Q_{u p}=\frac{Q_{\text {down }}}{k_{a s}}
$$

where $k_{a s}$ is the asymmetry coefficient, usually ranging from 1 to 4 .

To obtain the amount of the recovered energy which would be sufficient for traction of the 'upwards' moving train, the amounts of energy expressed by eqn. (3) and (4) should be equal. Comparing the data on the right side of the eqn. (3) and (4) and taking into account the eqn. (5), we will obtain:

$$
\left.S \cdot\left(Q_{\text {down }} \cdot\left|-i+w_{\text {down }}^{\prime \prime}\right|+P \cdot\left|-i+w_{0}^{\prime}\right|\right) \cdot k_{\text {rec }}=S \cdot\left(\frac{Q_{\text {down }}}{k_{\text {as }}} \cdot\left(i+w_{\text {up }}^{\prime \prime}\right)+P \cdot \mid i+w_{0}^{\prime}\right)\right) \text {. }
$$

The eqn. (6) is rearranged to define the energy recovery ratio:

$$
k_{\text {rec }}=\frac{\left(\frac{Q_{\text {down }}}{k_{\text {as }}} \cdot\left|i+w_{u p}^{\prime \prime}\right|+P \cdot \mid i+w_{0}^{\prime}\right)}{\left.\left(Q_{\text {down }} \cdot \mid-i+w_{\text {down }}^{\prime \prime}\right)+P \cdot \mid-i+w_{0}^{\prime}\right)} .
$$

When solving eqn. (7), it is assumed that all wagons of the train have four axles, while the jointed rails are used. The relative resistance of the locomotive moving along such a track depends on the train speed $v$ and the squared speed $v^{2}$, being calculated by the empirical equation [2]:

$$
w_{0}^{\prime}=2.4+0.011 \cdot v+0.00035 \cdot v^{2} .
$$

For loaded four-axle wagons (moving 'downwards') the relative resistance will be expressed as follows [2]:

$$
w_{\text {down }}^{\prime}=0.7+\frac{3+0.1 \cdot v+0.0025 \cdot v^{2}}{q_{a}},
$$

where $q_{a}$ is the axle load of a freight wagon, tf. For fully loaded wagons it is equal to $21 \mathrm{tf}$, for empty wagons $-6 \mathrm{tf}$. 
For empty four-axle wagons (moving 'upwards') the relative resistance is described by the expression [2]:

$$
w_{u p}^{\prime}=1+0.044 \cdot v+0.00024 \cdot v^{2} .
$$

A case is analysed, when the train with a mass of 4000 tons is moving 'downwards' at the speed of $80 \mathrm{~km} / \mathrm{h}$ along the straight track (with the curve radius equal to infinity), while another train with the mass of 1000 tons is moving 'upwards'. In this case, the unknowns in eqn. (7) are energy recovery ratio and the track gradient. The data used in solving eqn. 17 are given in Table 1.

Table 1: $\quad$ The data for solving the eqn. (7).

\begin{tabular}{|c|c|c|c|c|c|c|}
\hline $\begin{array}{c}Q_{\text {down }} \\
(\mathrm{t})\end{array}$ & $Q_{u p}=\frac{Q_{\text {down }}}{k_{\text {as }}}(\mathrm{t})$ & $\begin{array}{c}P_{\text {down }} \\
(\mathrm{t})\end{array}$ & $\begin{array}{c}w_{\text {down }}^{\prime \prime} \\
(\mathrm{kgf} / \mathrm{t})\end{array}$ & $\begin{array}{c}w_{0}^{\prime} \\
(\mathrm{kgf} / \mathrm{t})\end{array}$ & $\begin{array}{c}P_{u p} \\
(\mathrm{t})\end{array}$ & $\begin{array}{c}w_{u p}^{\prime \prime} \\
(\mathrm{kgf} / \mathrm{t})\end{array}$ \\
\hline 4000 & 1000 & 238 & 1.99 & 5.52 & 238 & 6.06 \\
\hline
\end{tabular}

For the system to function, energy recovery ratio should not be smaller than required. After substituting the data from Table 1 into eqn. (7), we will graphically show the dependence of the required energy recovery ratio on the track gradient (see Fig. 1).

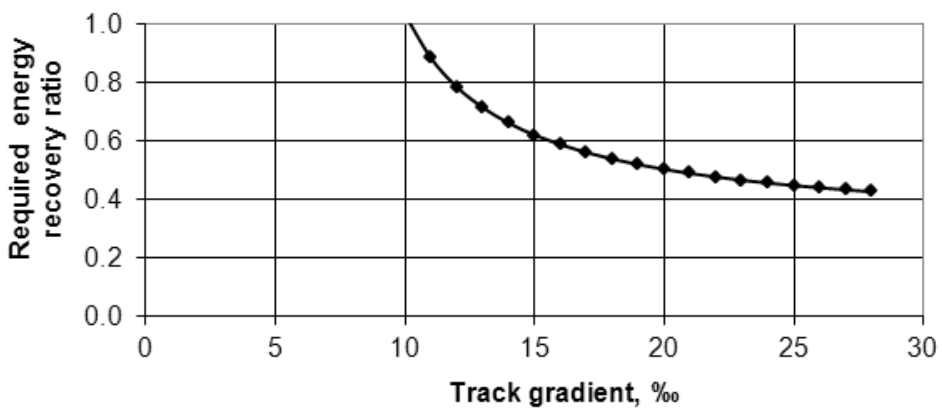

Figure 1: The dependence of the required energy recovery ratio on the track gradient.

The graph shows what should be the energy recovery ratio, fitting a particular track gradient, allowing the system to work without using any external source of energy. Modern technologies usually allow energy recovery ratio to be about 0.5 . As shown by the graphs presented in Fig 1, to ensure energy recovery ratio equal to 0.5 , the track gradient higher than $16 \%$ is required. 


\section{The study of the variation of energy recovery ratio}

\subsection{The analysis of the dependence of energy recovery ratio on the track gradient for varying speed of the train}

As shown by eqn. (7), the required energy recovery ratio depends not only on the track gradient, but also on primary running resistances $w_{0}$, which depend on the train speed (see eqns 8, 9 and 10). The running resistance, four axle values of the wagons (for the case of joined rails) are given in Table 2 with respect to the speed of the train.

Table 2: $\quad$ Running resistances of four-axle freight wagons given according to a particular speed of the train.

\begin{tabular}{|c|c|c|c|}
\hline $\begin{array}{c}\text { Speed } v \\
(\mathrm{~km} / \mathrm{h})\end{array}$ & $\begin{array}{c}\text { Locomotive } \\
\text { resistance } \\
w_{0}^{\prime}(\mathrm{kgf} / \mathrm{t})\end{array}$ & $\begin{array}{c}\text { Wagon resistance } \\
w_{u p}^{\prime \prime}(\mathrm{kgf} / \mathrm{t})\end{array}$ & $\begin{array}{c}\text { Wagon } \\
\text { resistance } \\
w_{\text {down }}^{\prime \prime}(\mathrm{kgf} / \mathrm{t})\end{array}$ \\
\hline 10 & 2.55 & 1.46 & 0.90 \\
\hline 20 & 2.76 & 1.98 & 0.99 \\
\hline 30 & 3.05 & 2.54 & 1.09 \\
\hline 40 & 3.40 & 3.14 & 1.22 \\
\hline 50 & 3.83 & 3.80 & 1.38 \\
\hline 60 & 4.32 & 4.50 & 1.56 \\
\hline 70 & 4.89 & 5.26 & 1.76 \\
\hline 80 & 5.52 & 6.06 & 1.99 \\
\hline
\end{tabular}

It is clear that the dependence of the required energy recovery ratio on the track gradient will vary with the variation of the train speed. This dependence obtained by substituting eqn. (7), (8) and (9) into eqn. (11) is demonstrated in Fig. 2.

It can be seen in Fig. 2 that energy recovery ratio increases with the speed increase. For example, when the speed is $20 \mathrm{~km} / \mathrm{h}$, while the track gradient is $15 \%$, the required energy recovery ratio is 0.4 . However, when the speed reaches $80 \mathrm{~km} / \mathrm{h}$, the above ratio is about 0.6 . In other words, the curve representing the dependence of energy recovery ratio on the track gradient rises up when the train speed increases. This is determined by the increase of primary running resistance of the accelerating train $w_{0}$, due to the friction of the axle box bearings, as well as the friction between the wheels and the rails, energy absorption by the railway embankment and aerodynamic resistance. The last component of primary running resistance, i.e. aerodynamic resistance, is rapidly increasing, when the train speed reaches $100 \mathrm{~km} / \mathrm{h}$ and more. It should be emphasized that primary running resistance of the train 'eats up' much energy in both types of train motion ('downwards' and 'upwards'). 


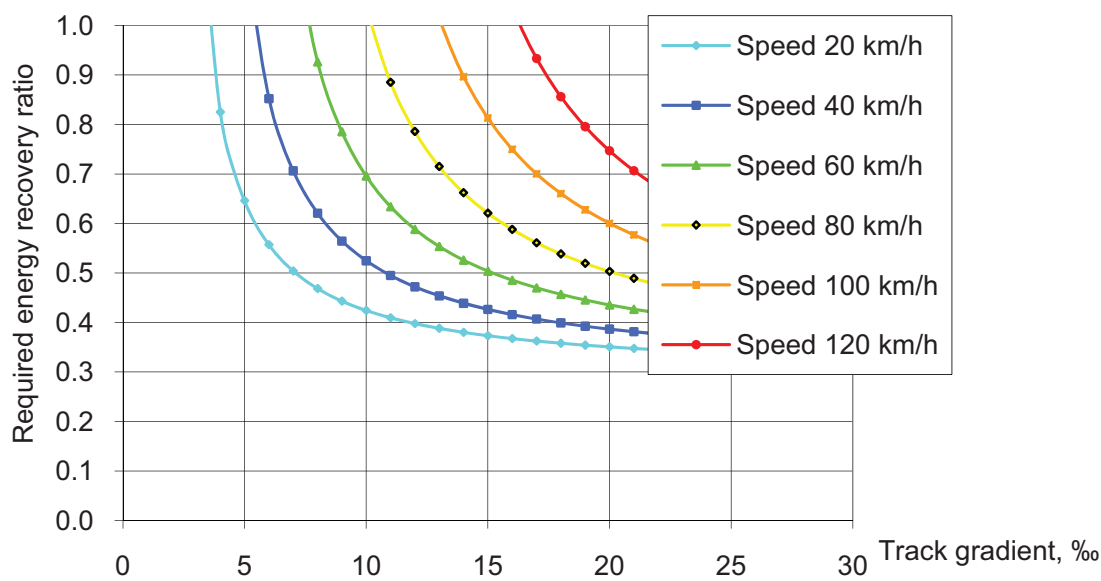

Figure 2: $\quad$ The dependence of energy recovery ratio on the track gradient for the train, moving at varying speed (the asymmetry coefficient $\left.k_{a s}=4\right)$.

\subsection{The analysis of the dependence of energy recovery ratio on the track gradient for the case of varying freight flow asymmetry}

The required energy recovery ratio varies with the variation of the asymmetry coefficient. The variation of the required energy recovery ratio, depending on the track gradient and the variation of the asymmetry coefficient, is shown in Fig. 3.

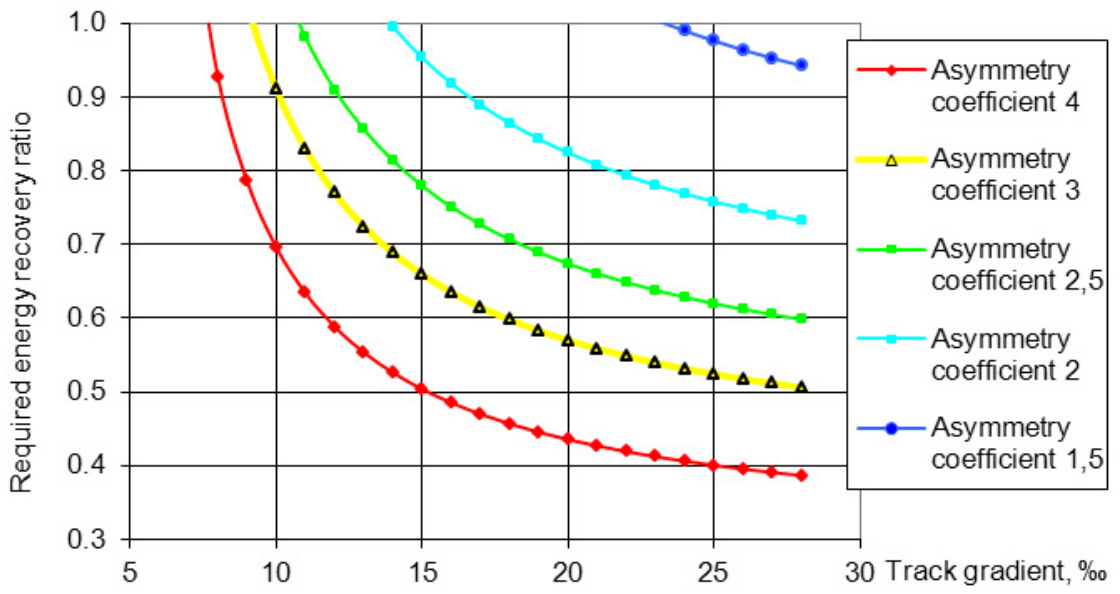

Figure 3: The variation of the dependence of the required energy recovery ratio on the track gradient for varying asymmetry coefficient. 
When the asymmetry coefficient decreases, the required energy recovery ratio increases. For example, when the track gradient is $15 \%$ and the asymmetry coefficient is 4 , the required energy recovery ratio is about 0.5 . However, when the asymmetry coefficient is equal to 2 , energy recovery ratio is about 0.9 . The curve showing the dependence of energy recovery ratio on the track gradient rises. When the asymmetry coefficient decreases, the mass of the train moving 'downwards' increases, and a certain amount of energy is stored due to the occurrence of downhill grades on the route. Most of this energy should be "returned" for pulling the train 'upwards'. It should be noted that the highest value of asymmetry coefficient is found when wagons moving 'downwards' are fully loaded, while those pulled 'upwards' are empty.

\subsection{The analysis of the dependence of energy recovery ratio on the track gradient for varying track curve radii}

So far, the cases with the straight track (when the value of the curve radius tends to infinity) have been considered. However, actual railway tracks are curved, and the moving train should overcome track curve resistance $w_{R}$, which is roughly calculated by the empirical equation [2]:

$$
w_{R}=\frac{700}{R} \text {, }
$$

where $R$ is an average radius of the track curves, $\mathrm{m}$.

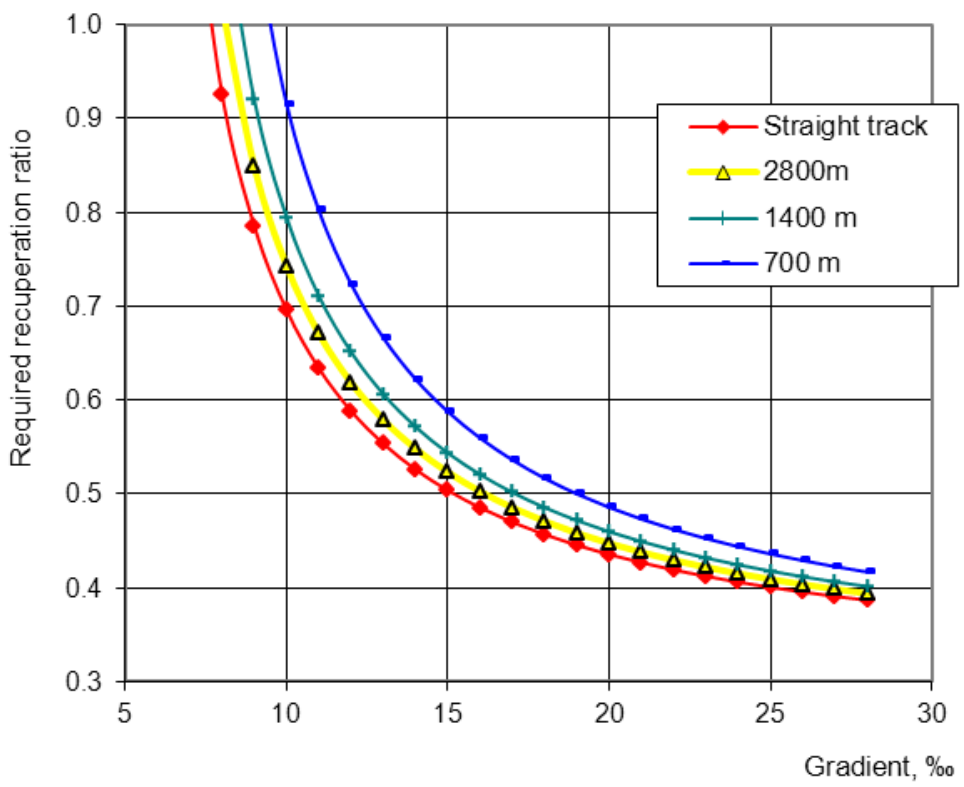

Figure 4: The dependence of the required energy recovery ratio on the track gradient, taking into account track curve radii. 
Taking into account the resistance of the curves, we may write the following equation:

$$
k_{\text {rec }}=\frac{\left(\frac{Q_{\text {down }}}{k_{\text {as }}} \cdot\left(i+w_{\text {up }}^{\prime \prime}+\frac{700}{R}\right)+P \cdot\left(i+w_{0}^{\prime}+\frac{700}{R}\right)\right)}{\left.\left(Q_{\text {dovn }} \cdot \mid-i+w_{\text {down }}^{\prime \prime}+\frac{700}{R}\right)+P \cdot\left|-i+w_{0}^{\prime}+\frac{700}{R}\right|\right)} .
$$

By substituting the data from Table 1 into the eqns (11), (8), (9) and (10) we will obtain a graph (see Fig. 4), when the train speed is $60 \mathrm{~km} / \mathrm{h}$.

When the average track curve radius decreases, the curve, showing the dependence of the required energy recovery ratio on the track gradient, rises, implying that the required energy recovery ratio increases because of the increase of track curve resistance (when the radii of the track curves are getting smaller). The resistances of the track curves 'eat up' much energy, when the train moves in either direction: 'upwards' or 'downwards'.

\section{Feasibility study of implementing the method of moving train energy recovery}

In studying feasibility of implementing the considered energy recovery method, special attention should be paid to two parameters - the track gradient and the required energy recovery ratio. At the present level of technological development energy recovery ratio may be about 0.5 . With the increasing use of alternative energy sources, it may be expected to reach 0.6-0.7. However, even with this value of energy recovery ratio, the described energy recovery method may be practically used, if the track gradient is more than $10 \%$ (which can be seen in Figures 1-4). In other words, either the track gradient should be higher than 10 $15 \%$, or energy recovery ratio should exceed $(0.6-0.7)$, which is hardly

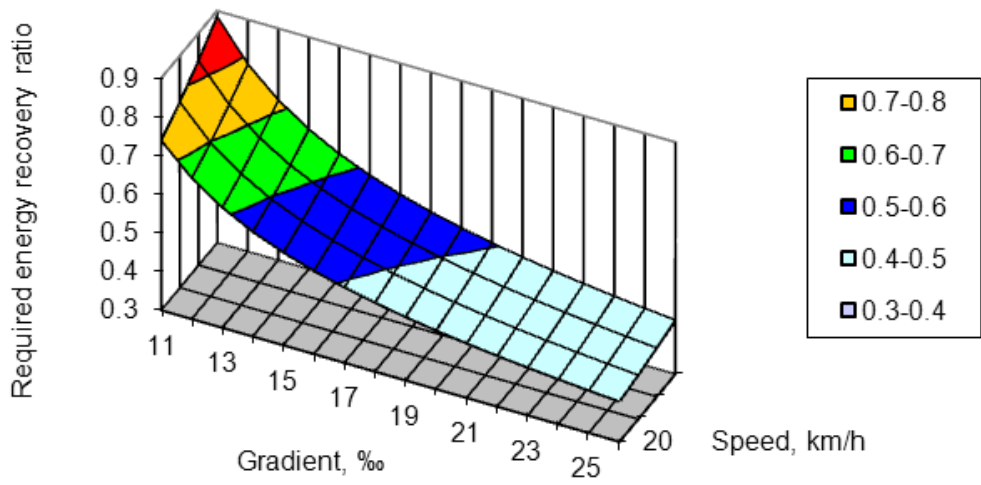

Figure 5: The dependence of the required energy recovery ratio on the track gradient and the speed of the 'upward' running train. 
technically possible. Such high slopes are rare in flat countries (like countries in Eastern and Middle Europe). Usually, the slopes there make 1-2\%, rarely reaching $5 \%$. When it is not technically possible to obtain the actual energy recovery ratio higher than $(0.6-0.7)$, the railway structure allows only for track gradient below $10 \%$ and the considered energy recovery method can be widely used. This means that the lack of energy of the train moving 'downwards' (required for pulling another train 'upwards') may be compensated by the energy obtained from another source. One of the simplest examples illustrating this statement could be a model, when the train is moving 'downwards' at a higher speed and moving 'upwards' at a lower speed. The dependence of the required energy recovery ratio on the track gradient and the speed of the train pulled 'upwards' (when the 'downward' speed is $80 \mathrm{~km} / \mathrm{h}$ ) is shown in Fig. 5 (in this case, energy recovery ratio ranging from 0.3 to 0.9 is considered).

As shown if Fig. 5, a decrease of the 'upward' speed does not produce a desired effect. If the required energy recovery ratio is assumed to be 0.5 , a decrease of the 'upward' speed from $80 \mathrm{~km} / \mathrm{h}$ to $20 \mathrm{~km} / \mathrm{h}$ results in the decrease of the required track gradient from $20 \%$ to $17 \%$. However, when the speed is decreased from 80 to $20 \mathrm{~km} / \mathrm{h}$ in both directions (see Fig. 2), the required energy recovery ratio is equal to 0.5 , while the track gradient is only $7 \%$.

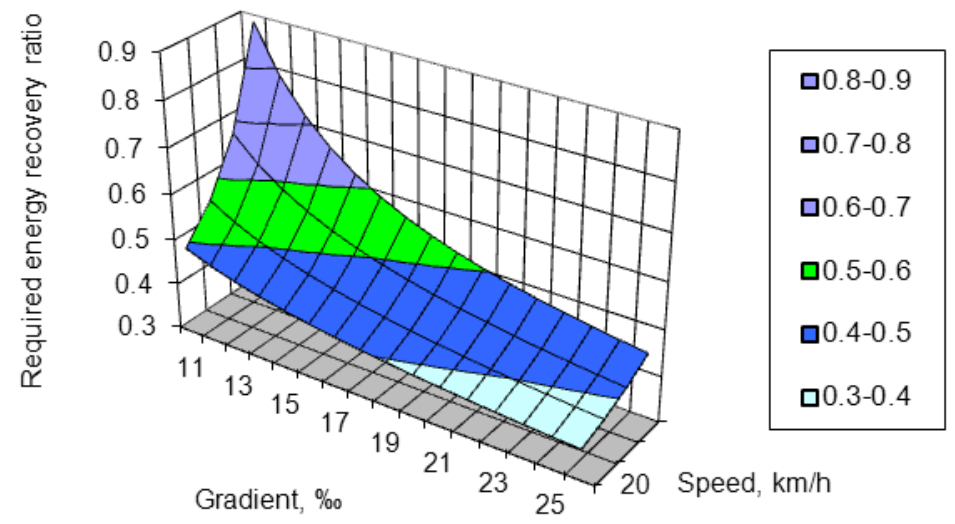

Figure 6: The dependence of the required energy recovery ratio on the track gradient and the speed of the train running 'downwards'.

The dependence of the required energy recovery ratio on the track gradient and the 'downward' speed of the train (whose 'upward' speed is $80 \mathrm{~km} / \mathrm{h}$ ) are shown in Fig. 6.

Fig. 6 presents a more valuable relationship than that given in Fig. 5. If the required energy recovery ratio is equal to 0.5 , then, a decrease of the 'downward' speed from 80 to $20 \mathrm{~km} / \mathrm{h}$ leads to a decrease of the track gradient from 20 to $11 \%$. It should be noted that the 'upward' speed of the train should not be lower than the speed of the train in continuous duty. The train speed in both directions should not exceed its design speed. It must be stressed, that the braking distance depends on the train speed, which should be limited too. 
The analysis of the relationships, presented in Figures 2, 5 and 6, allowed us to make a conclusion that, taking into account the dependence of the required energy recovery ratio on the track gradient, the most effective approach is to decrease the train speed in both directions of its movement. The next effective variant is a decrease of the 'downward' speed of the train, while a decrease of the 'upward' speed of the train is the least effective method. A mass of train running 'downwards' is (2-4) times as large as the mass of the train moving 'upwards', therefore, the speed of the train running 'downwards' has a stronger impact on the required energy recovery ratio.

\section{Conclusions}

1. Given the appropriate combination of the track gradient, running resistances and freight flow asymmetry, the potential energy of the carried goods can be used for freight carrying without any external energy source by applying energy recovery technique. However, required energy recovery ratio is necessary.

2. When the speed of the train increases, the required energy ratio also increases due to the increase of the main running resistance. In theory, energy recovery ratio can range from 0 to 1 , but because of technical limitations, it is usually about 0.5 .

3. The research performed has shown that pulling fully loaded wagons in one direction ('downwards') and empty wagons in the opposite direction ('upwards') is not ineffective from the perspective of energy recovery. In this case, the asymmetry coefficient reaches 4 , which is its highest value. This allows us to obtain the required minimum energy recovery ratio of 0.5 in operational conditions. Goods are carried in special wagons (tanks, hopers, etc.), whose asymmetry coefficient is about 4 . When the asymmetry coefficient decreases, the required energy recovery ratio increases.

4. In order to get larger amounts of the recovered energy in carrying goods by rail, wide curve tracks should be laid or straight tracks should be designed. When the average radius of the track curves decreases, the curve showing the dependence of the required energy recovery ratio on the track gradient rises. It implies that the required energy recovery ratio increases because of the increasing resistance (due to a decreasing track curve radius).

5. The analysis of the dependence of energy recovery ratio on the track gradient has shown that a decrease of the train speed in both directions is most effective, while the second effective alternative is a decrease of the 'downward' speed of the train. The third method, based on the decrease of the 'upward' speed of the train, is least effective for increasing energy recovery ratio.

6. The algorithms, developed in mathematical energy recovery analysis performed in the present work, may be used for optimizing the profile (track curves and gradients) of the newly laid tracks at the design stage. This can help to effectively use the potentialities of energy recovery technique in freight transportation by railway. 
7. The costs of laying the railway tracks of the profile adapted to energy recovery conditions will be paid off by the amount of recovery energy stored during the long years of freight transportation along the tracks of optimal profile.

\section{References}

[1] Bureika, G. A Mathematical Model of Train Continuous Motion Uphill. Transport, 23(2), pp. 35-137. 2008.

[2] Grebeniuk, P. T., Dolganov, A. N., Skvorcova, A. I. Traction calculations. Manual. Moscow: Transport. 272 p. 1987. (In Russian language).

[3] Klevzovich, S. Analysis of control systems for vehicle hybrid power trains. Transport 22(2), pp. 105-110. 2007.

[4] Liudvinavičius L., Lingaitis L. P. New locomotive energy management systems.//Maintenance and reliability = Eksploatacja i niezawodność/Polish Academy of Sciences Branch in Lublin. Warszawa. ISSN 1507-2711. No 1 (45), pp. 35-41. 2010.

[5] Liudvinavičius, L. Lingaitis, L. P. Electrodynamic braking in high-speed rail transport. Transport, 22 (3), pp. 178-186. 2007.

[6] Vaičiūnas, G. Optimal using of traction rolling-stock in Lithuanian Railways. Doctoral dissertation. Vilnius. 76 p. 2001. (In Lithuanian language). 